\title{
Two Early Astronomy Books
}

O W E N G I N G E R I C H

Among the three dozen early astronomy and mathematics books in the Special Collection Department at The University of Iowa Libraries, two are particularly outstanding: a first edition of Galileo's Dialogues on the Two Great World Systems (1632), and Tycho Brahe's Astronomiae Instauratae Mechanica (1602) (literally, "Instruments for the Reform of Astronomy").

Tycho Brahe's reputation deservedly rests on the observations made with the great instruments pictured in his Mechanica. Among sixteenth-century astronomers, he ranks second to Copernicus, and as an observer, he was clearly tops. Tycho was a child prodigy. At age 16 he was scandalized by the errors in the current astronomical tables, and he decided then to do something about it. His procedure eventually involved a couple of years of wandering among academic centers outside his native Denmark, and then some negotiations at the court in Copenhagen (delicately handled by his noble relatives) as to whether he could get support for an observatory. Tycho was granted the Island of Hveen as a fiefdom, and later he was to boast that his astronomical establishment had cost King Frederick II more than a ton of gold.

The astronomical institute of Hveen was complete not only with instruments (which Tycho developed experimentally over many years) but also with a printing press and even a paper mill. Nevertheless, Tycho finished the production of only one major book on Hveen: his De mundi aetherei recentioribus phenomenis ("Concerning the quite recent phenomena of the aethereal region"), and as this was privately distributed in only a few copies, it is today exceedingly rare. The major part of the printing of anther book, his Astronomiae instauratae progymnasmata ("Exercises for the Reform of Astronomy"), was carried out on Hveen, but it was still incomplete when, after 21 years on the island, Tycho decided in 1597 to emigrate to Prague. A new monarch had come to the Danish throne, and Tycho could no longer count on the same generous support; besides, the centrally located court of 
Rudolph II in Prague had a far more glamorous configuration of scientific talent.

Strangely enough, Tycho had not begun to publish his book of instruments while he remained on Hveen. Probably, because new devices were continually being developed, he never felt quite ready to press ink to paper to document his observatory. Once on the road, these reservations vanished and, perhaps in a burst of nostalgia, Tycho decided to record the glory of his Uraniborg, "The Celestial Palace." Thus it was in 1598 at a temporary stop in Wandesburg (near Hamburg) that he printed just enough copies for presentation to his friends and to set the stage for proper recognition at Rudolph's court. As for a more widespread and permanent edition to guarantee his reputation for posterity, that had to wait until 1602 for a posthumous printing in Nuremberg. There the same illustrative blocks were used with a new setting of type. The copy in the Iowa collection belongs to this latter edition; although more common than the 1598 version, it nevertheless is a very scarce item.

Despite being his own publisher, Tycho did not have a very welldeveloped typographic sense. His instrument book is a rough mixture of woodcuts and engravings, with type squeezed on the page without much regard for aesthetics. (This was in marked contrast to Johannes Kepler, who worked for ten months as Tycho's assistant at Prague; Kepler eventually owned his own number type for printing tables, and once reprinted the title page of one of his major works because the typography offended his taste.)

Nevertheless, the Mechanica accomplished Tycho's aims: it accurately commemorated one of the most remarkable advances in astronomical observing that the world has ever seen, an accomplishment all the more noteworthy when we realize that Tycho was the last great observer before the invention of the telescope.

The impact of the telescope, after Tycho, is reflected in another astronomical treasure in the special collections at Iowa. It is Galileo Galilei's most important work, the Dialogo . . . sopra i Due Massimi Sistemi del Mondo, Tolemaico, e Copernicano. Written in the everyday language, Italian, it had a large edition of 1,000 copies-and apparently over half the edition was sold out before the church authorities could move to prohibit it. Even today it is one of the more common classics in the history of science, but nevertheless it commands a substantial price because of its significance.

Galileo had written to Johannes Kepler as early as 1597 saying he was a Copernican, but it was another 13 years before he became an active enthusiast for the novel sun-centered cosmology. In 1609 he 
heard about a new invention, the telescope; on his own he figured out how it should work, and he made a series of ever-improved examples. At the end of 1609 he turned one of these to the moon, and to his astonishment he realized that the changing pattern of light could be interpreted as a landscape of mountains and plains. Early in January of 1610 Galileo discovered the satellites of Jupiter and by March he had in press a small pamphlet, the Sidereus nuncius or "The Starry Messenger," which described his findings. He began to use these and subsequent discoveries with considerable polemical skill to argue for the physical reality of the Copernican system. As long as the heliocentric system had been taught as a mere hypothesis, church authorities had tolerated its study. Galileo's own writings advocated the physical truth of the new system and the arguments from the "Book of Nature" suggested an alternative road to truth independent of the Holy Scripture. Hence the Inquisition moved to suppress Galileo's opinion, and in 1616 he was forbidden to teach or advocate the Copernican system.

In 1626, however, a new Pope came to the throne and Galileo received permission to write a "non-committal" discussion of the old and new cosmology. He couched his presentation in the form of a dialogue or debate between three scholars, but his superficially neutral stance fooled hardly anyone, probably not even the Florentine censor who gave his imprimatur or permission to print. Actually, the Dialogo piled one argument upon another against the Aristotelian physics and the geocentric system. Curiously enough, however, Galileo's argument from the tides, which he thought was the strongest of all, proved completely erroneous.

The aftermath of Galileo's publication is too well-known to recount here: he was brought before the Inquisition, forced to abjure his opinion on Copernicus, and placed under house arrest for the rest of his life. The Dialogo serves as a continual reminder not only of the crushing power of entrenched authority, but also of the ultimate impossibility of suppressing revolutionary new ideas. 


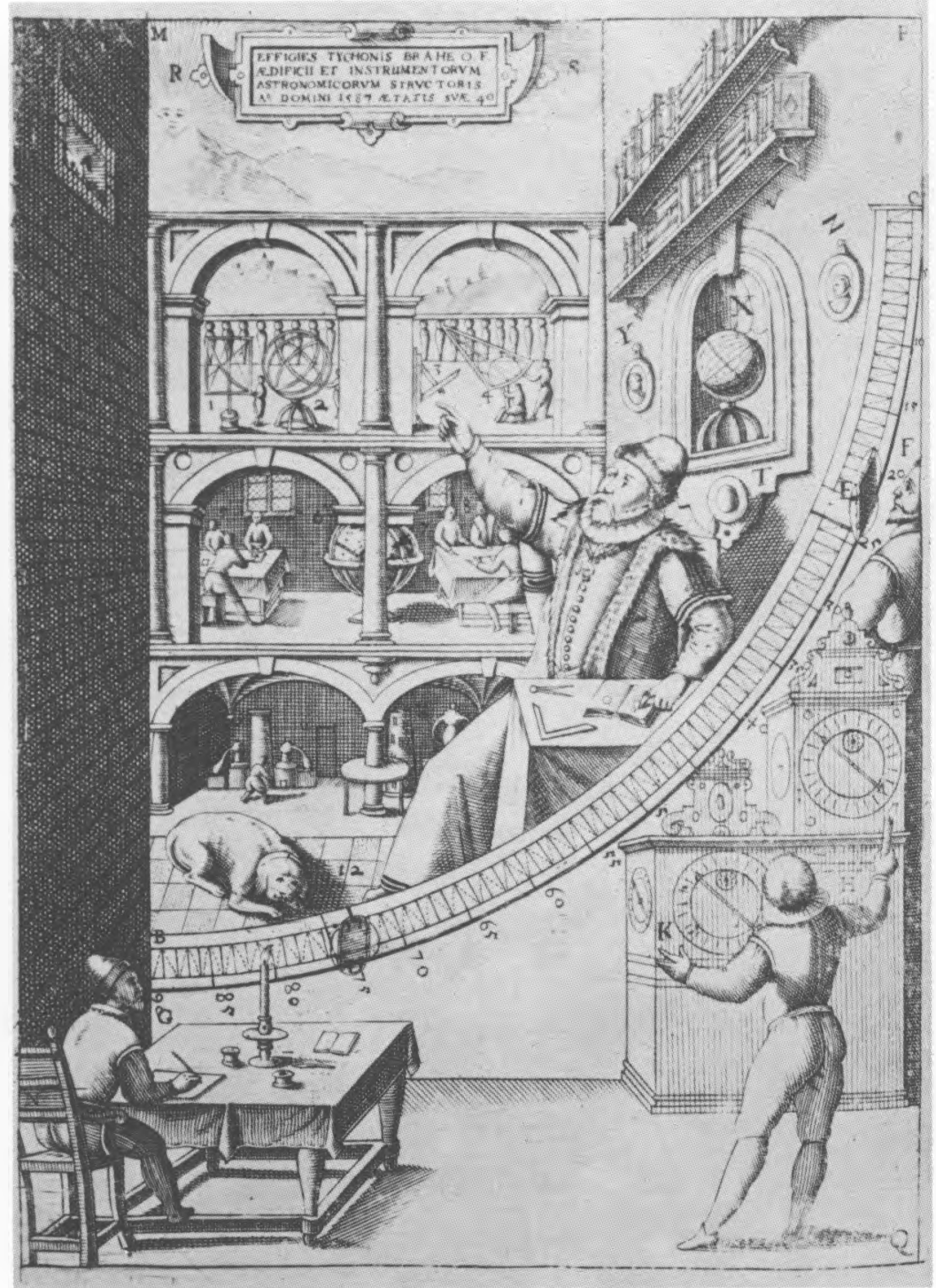

Tycho's great mural quadrant consisted of an arc with a 6.75-foot radius and two sliding sights. The wall on which the quadrant was mounted was adorned with a painting of Tycho by Tobias Gemperlin. Behind Tycho is depicted a cross section of Uraniborg showing the contents of several rooms. From a copy of Astronomiae Instauratae Mechanica (1602) owned by The University of Iowa Libraries. 


\section{ARMILL.E ALIÆ:AEQVA. TORIE.}

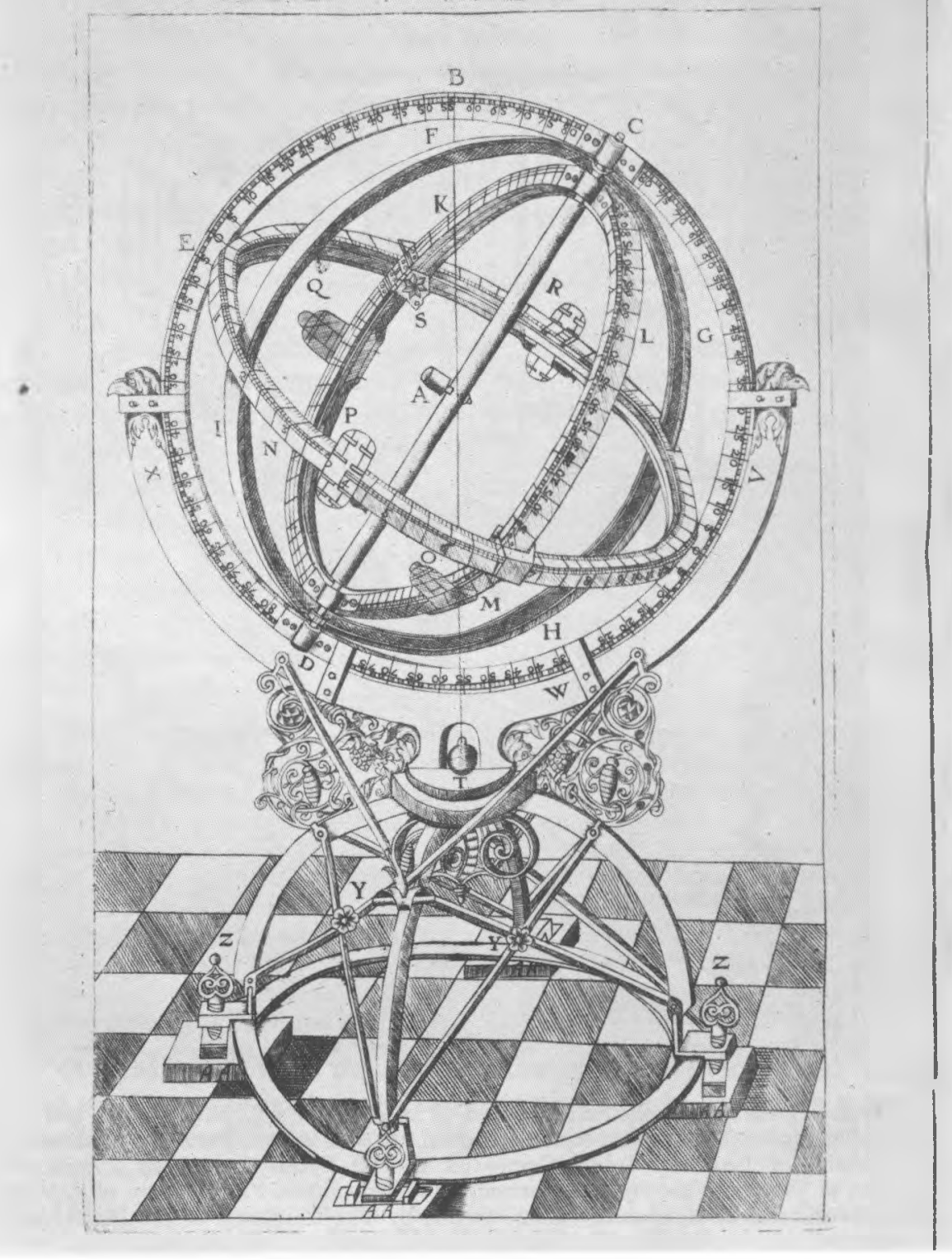

The years from 1584 to 1588 represented the apex of Tycho Brahe's career as an instrument maker. Probably the most important devices he developed during this period were the sturdy measuring machines known as equatorial armillaries. The armillaries, unlike sextants and quadrants, allowed Tycho to record celestial coordinates directly. From Astronomiae Instauratae Mechanica (1602).

http://ir.uiowa.edu/bai/vol30/iss1 